International Journal of Agriculture, Environment and Bioresearch

Vol. 5, No. 02; 2020

ISSN: $2456-8643$

\title{
BIO-LUBRICANTS: A RENEWABLE ALTERNATIVE TO MINERAL OILS
}

\author{
Andrew Ohifuemen \\ Research Officer, Technology Development Division, Rubber Research Institute of Nigeria, Benin City, Nigeria \\ Emmanuel A. Fagbemi \\ Senior Research Officer,Technology Development Division, Rubber Research Institute of Nigeria, Benin City, \\ Nigeria \\ Kolapo A. Fasina \\ Research Officer ,Biotechnology Division, Rubber research Institute of Nigeria, Benin City, Nigeria
}

https://doi.org/10.35410/IJAEB.2020.5487

\begin{abstract}
Environmental pollution has been on a meteoric rise since the early 20th century due to industrialization and petrochemical lubricants have played a major role in this regard. Biolubricants however, are derived mainly from vegetable oils, degradable to microorganisms, eco-friendly, and possess far better qualities when adequately processed. They have better viscosity indices, flash point, pour points, excellent lubricity, improved coefficient of friction and very skin compatible. They could be gotten from edible and non-edible oils such as vegetable oils (soybean, sunflower, canola, rapeseed, linseed and rubber seed oils), low viscosity polyalphaolefins, polyalkylene glycols among others. Without adequate treatment, they possess some shortfalls such as high oxidative activity, poor bio-resistance, poor hydrolytic stability and poor fluidity at lower temperatures. However, with chemical modifications such as acylation, epoxidation, partial hydrogenation and trans-esterification, these activities can be greatly eliminated. Recently, biotechnologists have been able to genetically modify some crops to reduce the linoleic acid and linoleic acid content of the seed oils while increasing its oleic acid characteristic. Thus, producing biolubricants with superior tribological characteristics. However, high costs of production has greatly limited the commercial production of biolubricants since it is a nascent technology, as against the environmentally-unfriendly petroleum lubricants. There is therefore need for more investigations in this field.
\end{abstract}

Keywords: Biolubricants, renewable, biodegradable, genetically modified oil.

\section{INTRODUCTION}

Machines, since the turn of the industrial age have been an important factor in the socioeconomic life of man. In recent times, significant interest has been focused on improving environmental friendliness, reliability, durability and energy efficiency in both automotive and machinery industries. This has led to the development of new technological solutions which include development of lightweight materials for use in building of machine parts, treatment of engine noises and exhaust gases and controlled fuel combustion [1]. 
The reliable, safe and efficient operation of any machine at optimum operatable conditions, require effective and adequate lubrication of moving parts to allow for free sliding movement of the parts with only mild wear and without excessive stresses on the parts while also reducing energy losses. While the main function of lubricants is to lubricate moving parts, they also help to clean the moving parts, inhibit corrosion, and improve sealing by carrying heat away from moving parts [2].

Lubrication as a branch of science reveals the need, cause and effect of the application of oils and grease to machines or engine parts. In engineering practise, the relative motion of two or more metal surfaces in contact with each other often results in friction, heat generation and the wearing out of the rubbing surfaces. This problem has been solved by applying substances (liquid or semi-liquid or solid) between the rubbing surfaces [3].

\section{DANGERS OF PETROLEUM LUBRICANTS}

Mineral oils, a type of lubricants derived from Petroleum crude oil, have been used as lubricants in internal combustion engines for a long time. Mineral oils are derived from crude oil in the same process that produces gasoline, kerosene and fuel oil (Diesel). They vary according to the type of crude oil and the refining methods used [4,5]. In addition, disposing of mineral oils leads to pollution of both aquatic and terrestrial ecosystems [6]. Trace metals such as calcium, phosphorus, magnesium and iron Nano-particles have been discovered to be released into the environment when mineral oils/ lubricants are not properly disposed for instance by burning $[7,8]$.

\section{REASONS FOR ALTERNATIVES}

The depletion of the world crude oil reserves and the moral burden placed on us to protect the environment against further pollution caused by lubricating oils and mindless spillage of petroleum lubricating and fuelling products have renewed interests in developing alternative lubricants [9]. Vegetable-based oils; classically referred to as Biolubricants, have now been developed to serve as alternatives to mineral oils. This is because they are renewable and ecofriendly, biodegradable and non-toxic, unlike conventional mineral based oils. Compared to mineral oils, biolubricants are known to possess and exhibit higher lubricity, higher viscosity index, higher flash point and low evaporative losses [10,11,12].

Vegetable oils can be obtained from over 300 oil bearing crops, according to world reports and these oils come under two broad classifications; edible and non-edible oils. The presence of long fatty acid chains as well as the presence of polar groups in the vegetable oil structure, makes it most suitable for use as lubricants [12].

\section{DESCRIPTION OF LUBRICANTS}

A lubricant is a substance that acts as a protective film between two sliding surfaces that are in contact. It helps to reduce friction and wear in machines, as well as improves movement between both surfaces. The primary function of a lubricant is to control as well as reduce friction. They possess desirable secondary benefits which could be summarized into five, including; 
1. They provide insulating properties in power transformers

2. They possess relatively high heat-sink capacity to cool contacting parts of machines

3. They remove wear particles

4. They are easily mixed with chemicals to give a variety of properties such as corrosion resistance, detergency or surface-active layers

5. They act as seal against dirt, dust and water [13].

There are four classes of lubricants including; oils (liquids), semi-solid (greases), solids (graphite and molybdenum) and gases. These classes of oils have been found to be produced from mineral oils, plant oil, synthetic oil or re-refined oil [14]. Typically, lubricants contain $90 \%$ base oil (most often petroleum fractions called mineral oils) and less than 10\% additives. Vegetable oils or synthetic liquids such as hydrogenated polyolefin, esters, silicon, fluorocarbons and many others are sometimes used as base oil in the production of lubricants [15].

A good lubricant should exhibit the following characteristics; high viscosity index, high boiling point, thermal stability, low freezing point, corrosion prevention capability and high resistance to oxidation.

\section{Biolubricants}

The term Biolubricants applies to all lubricants which have the tendency to be ingested, degraded and metabolised by microorganisms (biodegradable). They are non-toxic to humans and aquatic animals. The most important criteria for a substance to be referred to as a biolubricant is that it should be vegetable based or animal product based. Secondly, if it is from a synthetic source, the end product should be non-toxic and should be biodegradable [16].

Complete biodegradability indicates that the lubricant can be returned to nature. Partial degradability generally indicates that one or more components of the lubricants is not degradable. To classify the lubricant as potentially biodegradable, the degradation of $60 \%$ or greater of the lubricant must occur between $21-28$ days according to OECD 301, and greater than $80 \%$ in 21 days according to CECL $-33-\mathrm{A}-93$ method respectively [17].

Biodegradability is largely influenced by the base oil of lubricants. It depends on the chemical structures of the organic compounds that make up the biolubricant. Biodegradable oils include vegetable oils, low viscosity polyalphaolefins, polyalkylene glycols, dibasic acid esters, polyol esters among others. The biodegradabilty percentage of lubricant based oil are shown in Table 1.

Table 1: Biodegradability of some base fluids

\begin{tabular}{|l|l|}
\hline Types of Base Fluid & Biodegradability (\%) \\
\hline Mineral Oil & $20-30$ \\
\hline Vegetable oil & $95-98$ \\
\hline
\end{tabular}




\begin{tabular}{|l|l|}
\hline Esters & $75-100$ \\
\hline Polyols & $75-100$ \\
\hline
\end{tabular}

\section{Sources of Biolubricants}

It is observed that biolubricant feed stocks depend on climate and geographical locations. There are more than 350 oil bearing crops that may be used in producing alternative lubricants. The vegetable oils from which biodiesels have been produced are classified into two; edible and nonedible oils. Table 2 below shows examples of edible oils to include Palm oil, Soybean oil, Sunflower oil, Coconut oil, Rapeseed oil, Cottonseed oil, and Peanut oil, while non-edible oils include Linseed oil, Machua oil, Karanja oil, Jatropha oil, Castor oil and Rubber seed oil [19].

Table 2: Edible and Non-Edible oil Producing Crops.

\begin{tabular}{|l|l||l|l|}
\hline Edible Species & Oil Content (\%) & Non-Edible Species & Oil Content (\%) \\
\hline Rape Seed & $38-46$ & Jatropha & $40-60$ \\
\hline Palm & $30-50$ & Neem & $30-50$ \\
\hline Peanut & $45-55$ & Karanja & $30-50$ \\
\hline Olive & $45-70$ & Castor & $45-60$ \\
\hline Corn & Linseed & $35-45$ \\
\hline Coconut & Moringa & $20-36$ \\
\hline & $63-65$ & Mahua & $35-50$ \\
\hline & & Rubber Seed & $28-36$ \\
\hline
\end{tabular}

\section{Biolubricant Production}

Several techniques have been employed in the conversion of vegetable oils into biodegradable lubricants. The chemical modifications include acylation, epoxidation, partial hydrogenation and trans-esterification. The trans-esterification procedure is carried out either in a batch reactor or a continuous reactor. Vegetable oil which has been treated with sodium is first of all transesterified by reacting with ethyl hexanol. The temperature in the reactor is kept near the boiling point of the alcohol and the reaction is refluxed. The excess ethyl hexanol is distilled off under vacuum, after-which the lower layer of the trans-esterified oil is acidified to a $\mathrm{Ph}$ of $4-5$ and withdrawn. The upper oil layer dissolved in toluene is then refluxed with a "dean and stark trap" for the removal of water. The next step is to distil off the toluene, leaving the ester. The ester is then percolated over fuller's earth to remove organic acidity and obtain a straw yellow product. The modified vegetable oil is then characterised and heavy Alkyl Benzene is thoroughly mixed with it at $800 \mathrm{C}$ for 20 minutes. Finally, it is cooled down to $60 \mathrm{oC}$ for the addition of additives, after-which it is properly stirred for 30 mins to complete the formulation.

Vegetable oils and their esters are well known for their biodegradability. Automotive and industrial lube oils can also be formulated from the vegetable oil esters [20]. The most commonly optimised and salient properties of biolubricants are [21 -24]; 
3.1: Viscosity Index (VI): This is a number used to gauge oil viscosity change as a function of temperature. The viscosity of biolubricants does not vary with temperature as much as petroleum based lubricants. This is an advantage for designing of lubricants for use over a wide range of temperatures.

3.2: Pour Point (PP): This is the lowest temperature at which oil flows or pours. Pour point is an important factor vegetable oil based biolubricants have over their counterparts; mineral oils. They possess lower pour points, thus providing excellent lubrication for cold starts.

3.3: Low Volatility and High Flash/Fire Points: Flash point is the lowest temperature at which a lubricant must be heated before it vaporizes. Biolubricants have a very good record in applications like grinding, where there's a known fire hazard. This also results in oil mist reduction, thus reducing the inhalation of oil mist or oil vapours by machine operators.

3.4 Excellent Lubricity and Improved Coefficient of Friction: boundary lubrication occurs when oil viscosity is insufficient to prevent surface contact. The lubricity of bio based lubricants is about $2-4$ times their petroleum based corresponding lubricants. The wetting tendency of biolubricants helps in reduction of friction, often resulting in higher tool life. This reflects in the reduced mechanical losses and thus considerable energy saving of the equipment operation.

3.5 Dermatological benefit: Better skin compatibility and less harmful dermatological properties.

3.6 Biodegradability and non-water polluting: These characteristics reduce cost of disposal in addition to making them eco-friendly.

3.7 Minimise cost: Biolubricants are cost saving on account of less maintenance on the machinery due to possible longer intervals between re-lubrication.

3.8 Oxidation Stability: Oxidation stability is the ability for a biolubricant to exhibit resistance toward oxide forming tendencies, which increases as temperature rises. Bio lubricants have poor oxidation stability as base oils, hence oxidation inhibitors are required as additives when manufacturing them. However, studies carried out to genetically modify oil producing seeds such as soybean and rapeseed have been shown to tackle this problem effectively. Although the commercial application of such technology is yet to take full shape.

\section{Biodegradation Assessment}

The biodegradability of a biolubricant is best assessed using a "ready biodegradability test as published by the Organisation for Economic Cooperation and Development (44) and adopted by the European Union. In view of the solubility of biolubricants in water, only respirometric methods were found to be suitable for testing. The two recommended methods are OECD 301B and OECD 301F. They utilize some basic criteria in assessing biodegradability.

A substance is considered ultimately biodegradable (aerobic) if; 
a) In a 28 day biodegradation study according to OECD 301A-F or equivalent tests, the substance is completely harmless.

b) In OECD 301 tests based upon dissolved organic carbon, it is more than $70 \%$ degraded.

c) It can rapidly and extensively biodegrade in the environment.

d) It can be used in biodegradable or environmentally acceptable products.

Also, a substance is said to be inherently biodegradable if it shows;

a) Biodegradation that is greater than $20 \%$ but less than $60 \%$ after 28 days in OECD 301 tests

b) Based on oxygen depletion or carbon dioxide generation

c) Has only the potential to be degradable in the environment. [25].

\section{Application of Biolubricants}

Biolubricants can be used in the diverse applications such as hydraulic and gear oils, greases, engine oils, metal working fluids, and transmission oils. Their superior inherent qualities as well as their environmental compatibility favour their application in various sensitive environments without causing pollution [25 - 26]. The improved lubricity of biolubricants provides better tool life and better surface finish. Pure vegetable oils are used only in applications with low thermal requirements such as unmoulding and chainsaws.

\section{TOXICITY OF BIOLUBRICANTS}

Toxicity to the environment is an indication of pollution that could have direct impact of aquatic life, as well as indirect effect on human life. Hence, various studies have been carried out to elucidate the pathological effect on some selected aquatic life. Nemestotothy and his colleagues in 2012 from the Membrane Technology and Energetics department, University of Pannonia, Hungary, conducted an Acute Fish Toxicity Test of Fuel oil (biolubricant) on Zebrafish (Brachydanio rerio) in an aquatic environment. The Zebrafishes were assessed over an exposure period of 96 hours in a static system. It was conducted according to the OECD Guidelines for the Testing of Chemicals, Procedure No. 203 (1992). In this kind of test the limit in LC50 number (lethal concentration) is $100 \mathrm{mg} / \mathrm{l} \mathrm{[38].}$

In the second experiment, two 20 litre aquaria were used. While in the control experiment, there was no biolubricant, the other aquarium had a nominal concentration of $100 \mathrm{mg} / \mathrm{l}$. Zebrafishes (7 fishes in both aquaria), which are extremely sensitive to waste compounds, were the test animals used. Physicochemical properties (temperature, oxygen saturation, $\mathrm{pH}$ etc) of the water were measured. Observation of fishes were carried out at regular intervals $(3,6,24,48,72$ and 96 hours) and mortality was determined. At the end of the experiment, no pathological reactions or mortality were detected. Thus the $24 \mathrm{~h}, 48 \mathrm{~h}, 72 \mathrm{~h}$ and $96 \mathrm{~h}$ LC50 number of the particular biolubricant was greater than $100 \mathrm{mg} / \mathrm{l}$. This suggested from their study that the biolubricant was not toxic to the Zebrafish in the water body [39-40]. 
Vol. 5, No. 02; 2020

ISSN: $2456-8643$

\section{SHORT FALLS OF BIOLUBRICANTS}

In contrast to mineral oil based lubricants, vegetable oils in direct use as biolubricants, have some disadvantages because of a variety of factors. The first shortfall portends from the presence of acyl groups in Vegetable oils, which results in the poor oxidative and thermal stability of Vegetable oils. The presence of glycerol backbone in these oils gives rise to a tertiary $\beta$ hydrogen, which is thermally unstable [24]. This low oxidative stability of vegetable oil causes it to oxidise rapidly during use if it is not pre-treated, becoming thick and polymerising to a plastic like consistency.

The major component of vegetable oils is a triglyceride of long chain fatty acids of mostly unsaturated carbon atoms. The double bonds of the fatty acid chains are mostly unconjugated. Thus, they have low thermo-oxidative stability, poor bio-resistance, poor hydrolytic stability and poor fluidity at lower temperatures $\left(25-27^{\circ} \mathrm{C}\right)$. Therefore, they cannot be used directly as lubricant-based stocks or additives. Secondly, the presence of bis-allysic protons in the chains makes Vegetable oils very prone to oxidative degradation [28]. This ultimately results in an insoluble deposit formation in vegetable oils which increases oil acidity, viscosity, corrosion and volatility.

Another shortfall of vegetable oils is their higher cost of production compared with mineral lubricants for commercial purposes. These limitations can however be mitigated through chemically modifying vegetable oils to reach a desirable performance level without increasing the cost.

In order to mitigate the low oxidative and thermal stability of Vegetable oils, certain physicochemical methods have been developed. These include the use of catalysts, emulsion method, alkylation, epoxidation, acylation and hydrofomylation. Unfortunately however, use of these substitution methods tend to reduce the biodegradability of Vegetable oils [30]. Alternatively, the use of additives could help to improve the quality of the oils without altering the biodegrability of the oil. The cost of production is another factor that has prevented the wide spread use of biolubricants [29]. Another viable option is the use of genetically modified oils.

\section{GENETICALLY MODIFIED VEGETABLE OILS}

Genetically modified lubricants production is a pretty new concept that has largely taken over the scene, since the discovery of recent techniques in genetically engineering living organisms. As the name suggests, genetically modified lubricants are derived from oils produced from genetically modified plants. Since every phenotypic character of an organism is largely determined by the information stored in its chromosomal or plasmid DNA, a modification in that nucleic acid will ultimately result in an altered phenotypic expression.

Genetic engineers have successfully exploited this technology in modifying biological systems in order to achieve desired traits in microorganisms, plants and animals. Plants that have undergone successful genetic modification include sunflower, soybean, rice, cotton, canola [45]. 
In the lubrication industry, the objective of genetic modification is to manufacture oils that have higher degrees of saturation, in such a way that will reduce its susceptibility to oxidative deterioration by means of exposed double bonds in the fatty acid molecules [43]. The genetic sequence of the plants such that the linolenic and linoleic acid contents of crops like sunflower, soybean and canola are reduced, while the olieic acid contents of the oils are increased. Thus the thermal and oxidative stability of the lubricating oils derived from such plants' seeds will be improved without altering its biodegradability [38-40].

Through genetic modification of vegetable oils, the cold-flow properties of the lubricants could also be improved such that at low temperatures of the temperate regions, they would be stable and act as lubricants. Other properties that could be improved include having higher proportions of short-chain saturated or long-chain monounsaturated fatty acids in the oil, thereby lowering lower the pour point for better tribolity [41, 42].

\section{CONCLUSION}

The biolubricant market has increased at an approximate rate of $10 \%$ per year globally in the last two decades [31]. The driving forces of such increase are mainly the growing awareness regarding environment friendly products and government incentives and regulations. When compared to the mineral oil market, the biolubricants usage is very small, and concentrated in some countries of Europe and in the United States of America (U.S.A). The biggest challenge to the industries is how to reduce the production costs of biolubricants from vegetable oils, therefore making its prices attractive.

As the years have gone by and technology have improved, the awareness and research into vegetable based oils as an important part of developing new strategies, policies, and subsidies that aid in reducing the dependence on mineral oil and other non-renewable sources have been on a steady rise. It is hoped that in the not too distant future, the use of vegetable based oils would have gained as much traction in use round the world.

Acknowledgement

The authors would love to acknowledge the financial and moral support of Dr A.I. Aigbodion the Executive Director, Rubber Resaerch Institute of Nigeria, Iyanomo, Nigeria.

\section{REFERENCES}

1.Gerbig Y, Ahmed S.I.U, Gerbig F.A, Haefke H. (2004): Suitability of Vegetable oils as Industrial Lubricants. J Synth Lubr. 2004; 21: 177-91

2.Wamma and Dieter. Lubricants and Related Products, Verlag Chemic (1984) ISBN $\quad 0-$ 89573-177-0

3.Abdulraheem A.M.O, Adebayo A.A, Adekola F.A,. Physico-Chemical Properties of Fresh Blend and Used Motor Oils. Proceedings of First Kwara Chapter Chemical Society of Nigeria Conference (2008); 97-99. 
Vol. 5, No. 02; 2020

ISSN: $2456-8643$

4.Berry James. Oil Whirl and Whip Instabilities within Journal Bearing. Machine Lubrication Magazine 2005.

5.Ofodu .J.C and Anosike .C. Variation in Rheological Properties of Engine Oils with Usage. Global Journal of Engineering research (1993); 2(1 \& 2): 95-100

6.Jsempeba .J.C, Carpenter D.D,. The Generation, Use and Disposal of Waste Crankcase Oil in Developing Countries; A case for kampala district, Uganda. J Hazard Mater (2001); Issue 161; $835-841$.

7.Miller A.L., Stipe C.B, Habjan M.C, Gilbert A.G, Role of Lubrication Oil Particulate Emissions from a Hydrgen-Powered Internal Combustion Engine. Environmental Science Technology (2007): 41; (6828-35).

8. Tung S.C, McMillan M.L, Automotive Tribology Overview of Current Advances and Challenges for the Future. Tribol Int. (2004): 37; 517-536

9.Lathi P.S, Mattiasson B. Green Approach for Preparation of Biodegradable Lubricant Base Stock from Epoxidised Vegetable Oil. Tribol Int. (2007): 69; 207-222.

10.Ravasio N., Zachena F.,Gargano M., Recchia S., Fuji A., Foli N., Psaro R., Environmental Friendly Lubricants through selective Hydrogenation of Rapeseed oil over Supported Copper Catalyst. App Cat. A (2002); 233; 1-6.

11.Nagendramma Pomekanti, Kaul Sivita. Development of Ecofriendly/Biodegradable Lubricants: an overview, Renewable Sustain Energy Review. (2012); 16: 164-174.

12.Dinda S., Patwardhan A.V., Goyd V.V., and Pradhan N.C., Epoxidation of Cottonseed Oil by aqueous Hydrogen Peroxide catalysed by Liquid Inorganic Solids. Bioresource Technology (2008); 99: 3737-3744

13.Lasdown A., Lubrication and Lubricant Selection: A Practical Guide. 2004: ASME.

14.Askew M.F. IENICA: Biolubricant Market Data Sheet, Central Science Laboratory, (2004), UK.

15.George E. Totten; CRC Handbook of Lubrication and Tribology, Vol 1; Edition 2.

16.Rahal Gokhale, Karmarkar A.S, Emerging Trends and benefits of Biolubricants, (2010).

17.Salimon J., Salih H., Emad Y., Biolubricants: Raw Material, Chemical Modifications and Environmental Benefits Review article. European Journal of Lipid science and Technology, (2010), 112 (5); $519-530$.

18.Batters N.S. Biodegradable Lubricant, What does biodegradable really mean? J Synth Lubricant (2005); 22: 3-18. 
19.Sharma Y., Singh B., An Ideal Feed Stock, Kusum (Schleichera trigus) for Preparation of Biodiesel: Optimisation of Parameters Fuel (2010); 89: 1470-1474.

20Singh A.K, Development of Biodegradable Lubricant. Chemical Business (ISSN 970 - 3136) 22 (4) April (2008), pp 53-55.

21.Willing A.; Lubricants based on Renewable Resource - an Environmentally Compatible Alternative to Mineral oil products. Chemosphere (2001): 43; 89 - 98.

22. Asadauskas S., Perez J.M, Duda J.L, Oxidative Satbility and Anti-wear properties of High Oleic Vegetable Oils. Lubr. Eng (1996); 52: 877-882.

23.Fox N.J, Stachiowiak G.W., Vegetable Based Lubricants - A Review; Tribol Int. (2007); 40: 101-110.

24.Salimon J., Salih H., Emad Y., Biolubricants: Raw Materials, Chemical Modification and Environmental Benefits. Review Article. European Journal of Lipid Science and Technology. (2010): 112 (5): 519-530.

25.Mofijur, M.; Masjuki, H.H., Kalam, M.A., Shahabuddin, M., Hazrat,. Liaquat, A.M. Palm oil methyl ester and its emulsion effect on lubricant performance and engine components wear.Energy procedia (2012), 14, 1748-1753

26.Liu, Z., Sharma, B.K., Erhan, S.Z., Biswas, A., Wang, R., Schuman, T.P. Oxidation and low temperature stability of polymerized soybean oil-based lubricants. Thermochim. Acta (2015), 601, 9-16

27.Adhvaryu, A, Erhan, S.V., Liu, Z.S., Perez, J.M. Oxidation and kinetic studies of unmodified and genetically modified vegetable oils using pressurized differential scanning calorimetry and nuclear magnetic resonance spectroscopy. Thermochim. Acta (2000): 364, 87-97

28.Fox, N.J, Stachowiak, G.W. Vegetable oil-based lubricants-A review of oxidation. Tribol. Int. (2007), 40, 1035-1046

29.Igartua A., Terradillo J., Areitiogurtena .O., Marchide .A., Fernandez .X., Lube Magazine, Biodegradable Lubricants, (2007): 82; 55; 1-4.

30.Leugner .L., The Practical Handbook of Machinery Lubrication, 2nd Edition, Canada. Maintenance Technology International Inc Pp 75-76, 144, 149.

31. Schneider P.M. Plant-oil based Lubricants and Hydraulic Fluids. A Review. Journal of the science of food and Agriculture (2006); 86: 1769-1780.

32.Erhan .S.Z., Sharma .B.K., Liu Z., Adhvaryu .A., Lubricant Base Stock Potential of Chemically Modified Vegetable Oils. Agric Food Chemistry, Vol 56, Pp 8919 - 8925

38. Smith, S. A., King, R. E., and Min, D. B., Oxidative and thermal stabilities of genetically modified high oleic sunflower oil. Food Chemistry. (2007): 102(4), 1208-1213. 
39. Marmesat, S., Morales, A., Velasco, J., and Carmen Dobarganes, M., Influence of fatty acid composition on chemical changes in blends of sunflower oils during thermoxidation and frying. Food Chemistry. (2012): 135(4), 2333-2339.

40. Fox, N. J., and Stachowiak, G. W., Vegetable oil-based lubricants: A review of oxidation. Tribology International. (2007): 40(7), 1035-1046.

41. Jayadas, N. H., and Nair, K. P., Coconut oil as base oil for industrial lubricants-Evaluation and modification of thermal, oxidative and low temperature properties. Tribology International. (2006): 39 (9), 873-878

42. Zeman, A., Sprengel, A., Niedermeier, D., and Spath, M., Biodegradable lubricants studies on thermo-oxidation of metal-working and hydraulic fluids by differential scanning calorimetry (DSC). Thermochimica Acta. (1995): 268, 9-15.

43. Mendoza, G., Igartua A, Fernandez-Diaz, B., Urquiola, F., Vivanco, S., and Arguizoniz, R., Vegetable oils as hydraulic fluids for agricultural applications. Grasas Aceites. (2011): 62(1), 29-38.

44.Organisation for Economic Cooperation and Development, Guidelines for testing of chemicals. Adopted by the Council on 17th July 1992. 